\title{
eParticipation Research: A Longitudinal Overview
}

\author{
Rony Medaglia \\ Department of IT Management, \\ Copenhagen Business School, Howitzvej 60, \\ 2000 Frederiksberg, Denmark \\ rm. caictacbs. dk
}

\begin{abstract}
This paper provides an update of the existing eParticipation research state of the art, and a longitudinal analysis of the development of the eParticipation field based on a shared framework of analysis. Drawing on a literature search covering the period from April 2006 to March 2011 included, 123 articles are identified, analysed and classified within the categories of eParticipation actors, activities, contextual factors, effects, and evaluation. Findings show that the field has a high level of dynamism, as focuses on eParticipation activities, contextual factors and effects have shifted in time, sometimes in counterintuitive directions. Drawing on the analysis, the conclusion section provides inputs for a research agenda. These include the need to move beyond a technological perspective, and encouraging the ongoing shift of research focus from government to citizens and other stakeholders.
\end{abstract}

Keywords: eParticipation, eDemocracy, literature review.

\section{Introduction}

The growing body of knowledge on eParticipation in recent years has increased the complexity of the research field. Contributions focusing on the emergence of new forms of citizen participation in political activity through information and communication technologies (ICT) come from a wide range of disciplines [1]. eParticipation research includes perspectives from political science, sociology, management, psychology, economics, together with contributions that are more technical in nature. Such a varied scenario of disciplinary backgrounds is also accompanied by a variety of methodological stances, and normative perspectives characterizing eParticipation research [2].

As a result of this complexity, a number of attempts at scoping the research field have been carried out so far [1], [3-6]. These contributions aim at providing comprehensive views of the research area, and to enable the research community to share a set of epistemological tools in order to identify gaps and advance the research field. Nevertheless, since eParticipation can be considered a field that is still on its way towards maturity, there is a need to refine the scenario of the state of the art of research available. Existing reviews, being the first ones, still fail to build on top of each other in a systematic way. This can represent a relevant burden as far as understanding the direction that the eParticipation research field is taking in time is concerned. 
This paper aims at updating the understanding of the scenario of eParticipation research, while providing a longitudinal analysis of its developments. In particular, this review mainly draws on the approach adopted in Sæbø et al. [5].

The article is structured as follows. The following section will present the method used and the strategy adopted for collecting the literature data on eParticipation research. Section 3 outlines and discusses the limitations of the study. Section 4 will introduce the categories used for the literature analysis. Section 5 will present the findings, distinguishing between five main categories of research focus: eParticipation actors, eParticipation activities, contextual factors, eParticipation effects, and eParticipation evaluation. The conclusion section summarizes the contribution of the paper and provides inputs for an eParticipation research agenda.

\section{Method}

This paper draws on the analysis of the most recent contributions on eParticipation. The literature search includes all eParticipation-related research contributions published in international journals and conferences in the period from April 2006 to March 2011 included.

The search was conducted via EBSCO, ISI Web of Knowledge, and IEEE Explore databases, in line with the guidelines provided by Webster and Watson [7]. This approach has been adopted in order to capture what are deemed to be all the internationally relevant research contributions, coming from established journals and conferences. The three databases index more than 8,000 journals in the fields of natural sciences, social sciences, and humanities, including important public administration journals, such as Government Information Quarterly and Public Administration Review, and the top journals in the Information Systems field. Relevant conferences include, among others, the DEXA cluster (including EGOV and ePart conferences), and the Hawaii International Conference on System Sciences (HICSS). A separate search was conducted through the AIS Electronic Library (AISeL), in order to include articles from the proceedings of the European Conference on Information Systems (ECIS) and the International Conference on Information Systems (ICIS).

The literature review carried out in this article draws on the selection strategy adopted in Sæbø et al. [5]. Therefore, in order to retrieve a first comprehensive group of research articles related to eParticipation, the literature databases listed above have been searched using the following sets of keywords in the abstract and the title:

1. eDemocracy, using additional search phrases: eDemocracy, electronic democracy, democracy and Internet, democracy and information system, digital democracy.

2. eParticipation, using additional search phrases: eParticipation, electronic participation, eGovernment and participation, eGovernance and participation, eConsultation, ePetition.

3. eInclusion, using additional search phrase: digital divide and participation (within the results of "digital divide", since "digital divide" only returned more than 450 hits $)^{1}$.

${ }^{1}$ Alternative spellings for some of the keywords were also used to maximize the literature coverage (e.g.: e-democracy; e.participation; e-petition, etc.). 
The keywords used are intended to cover the topic area of ICT and democratic participation, including research contributions that do not explicitly use the term eParticipation. A first keyword search was performed in the period between July and October 2008, covering all publications in the period from April 2006, which is the first month not covered by the previous literature review by Sæbø et al. [5], to October 2008 (included). A second keyword search was performed in March 2011, covering the period from November 2008 to March 2011. The approximate 500 bibliographical items retrieved through the keyword search had their titles and abstracts scanned, in order to identify contributions clearly falling under the scope of eParticipation. eParticipation was referred to as the use of IT to support democratic decision-making. This definition of eParticipation draws on the one provided by Macintosh [8], where eParticipation is related to the issues of enabling opportunities for consultation and dialogue between government and citizens by using a range of IT tools. The definition provided by Macintosh [8] has been also extended to include eVoting, that is the use of ICT to support the democratic process of voting. As a result, 123 full text articles were retrieved, analysed and classified by the author, according to the categories described. It was possible for articles to be included in different categories, therefore the total number of category occurrences is higher than the number of articles.

\section{Limitations}

A number of limitations in this approach have to be taken into account. First, the scope of the literature search includes only contributions written in English, which implies that significant pieces of research on eParticipation that are written in languages other than English have not been taken into account. Such a limitation is significant if we consider that, in theory, a relevant portion of eParticipation research at national and local level can be published in national languages other than English.

Second, while the databases reviewed can be easily argued to be among the most comprehensive ones, the literature scan did not include some academic sources where eParticipation research can appear, such as the proceedings of the European Conference on E-Government, and the International Conference on E-Government.

Third, the choice of keywords might be considered as incomplete and therefore overlooking research that could be argued to fall within the domain of eParticipation. While the bias introduced by the choice of any limited set of keywords - as the one by Sæbø et al. [5] - is unavoidable, the advantage of using the same set of keywords at different times has to be underlined, as it provides a robust foundation for longitudinal comparison.

Last, the classification process, following the categories presented in the next section, has been carried out by the author only, trying to subjectively replicate the underlying criteria of the distribution of articles between the categories emerging in Sæbø et al. [5], without external aid from other researchers. While this is clearly a limitation that can impact the validity of the findings, there are examples of well-cited reviews in high level outlets that have followed the same approach [9]. 


\section{Classification of the Research Domain}

The main categories used to classify and capture the development of the eParticipation field were initially drawn from the model of the field presented by Sæbø et al. [5], to ensure a good degree of continuity and longitudinal comparability in the analysis of the development of the eParticipation research field.

The list of categories in the model, without reference to the relationship between them, is here adopted as a guideline. Each category refers to a focus adopted by the research analysed, namely:

* eParticipation actors (Citizens; Politicians; Government institutions; Voluntary organizations);

* eParticipation activities (eVoting; Online political discourse; Online decision making; eActivism; eConsultation; eCampaigning; ePetitioning);

* Contextual factors (Information availability; Infrastructure; Underlying technologies; Accessibility; Policy and legal issues; Governmental organization);

* eParticipation effects (Civic engagements effects; Deliberative effects; Democratic effects);

* eParticipation evaluation (Quantity of eParticipation; Demographic of participants; Tone and style in the online activities)

The range of categories has been expanded when new contributions in the sample analyzed could not fit into the existing categories. This resulted in introducing the actor category of researchers and scholars, as also suggested by [10], and the evaluation category of transparency and openness. Each article has been assigned to one or more categories, depending on the main research contribution(s).

The following section provides a presentation of the findings from the analysis of the literature carried out using the method and the classification categories described.

\section{Findings and Discussion}

This section outlines the eParticipation field by exploring international eParticipation research contributions related to the following categories: actors, activities, contextual factors, effects, and evaluation.

Table 1 provides an overview of the distribution of all bibliographical items on the categories of analysis. The total number of contributions in each period is higher than the correspondent total $\mathrm{N}$ of articles, as each article can include more contributions to different categories.

The research field of eParticipation is growing rapidly, even though it can still be considered to be in its early stages. The previous literature scan, based on all years of available publications until March 2006, has discussed a total of 93 articles in its findings [5]. The period of this study, April 2006-March 2011, features 123 eParticipation-related contributions. In other words, since the last literature overview, an average of almost two new eParticipation studies has been published every month. 
Table 1. Overview of eParticipation contributions

\begin{tabular}{|c|c|c|}
\hline Category & $\begin{array}{l}\text { Up to Mar } 2006 \\
(N=93)[5]\end{array}$ & $\begin{array}{l}\text { Apr 2006-Mar } \\
2011(N=123)\end{array}$ \\
\hline Citizens & 9 & 13 \\
\hline Government institutions & 8 & 8 \\
\hline Voluntary organizations & 7 & 6 \\
\hline Politicians & 5 & 5 \\
\hline Researchers and scholars & $\mathrm{n} / \mathrm{a}$ & 1 \\
\hline eParticipation actors (total) & 29 & 33 \\
\hline eVoting & 13 & 11 \\
\hline Online decision making & 18 & 8 \\
\hline Online political discourse & 15 & 7 \\
\hline eConsultation & 8 & 5 \\
\hline eActivism & 9 & 3 \\
\hline eCampaigning & 3 & 2 \\
\hline ePetitioning & 2 & 1 \\
\hline eParticipation activities (total) & 68 & 37 \\
\hline Underlying technologies & 11 & 27 \\
\hline Accessibility & 8 & 0 \\
\hline Infrastructure & 8 & 2 \\
\hline Governmental organization & 7 & 12 \\
\hline Information availability & 5 & 0 \\
\hline Policy and legal issues & 3 & 1 \\
\hline Contextual factors (total) & 42 & 42 \\
\hline Civic engagement effects & 8 & 9 \\
\hline Democratic effects & 3 & 9 \\
\hline Deliberative effects & 1 & 10 \\
\hline Quantity of eParticipation & 4 & 8 \\
\hline Demographic of participants & 1 & 5 \\
\hline Tone and style in the online activities & 1 & 7 \\
\hline Transparency and openness & $\mathrm{n} / \mathrm{a}$ & 11 \\
\hline eParticipation effects \& evaluation (total) & 18 & 59 \\
\hline
\end{tabular}

The picture of the international eParticipation research scenario first provides a number of interesting insights into the current state and future development of the field, when we look at the changes in focus through time.

Overall, research on eParticipation has experienced a big shift in focus away from activities, towards the study of eParticipation effects and evaluation. This has happened within the context of a general redistribution of focuses, resulting in a more balanced picture of contributions focusing respectively on actors, activities, contextual factors, and effects and evaluation. The emergence of a balance between focuses on different aspects of eParticipation can be interpreted as a move towards a higher degree of maturity of the field: different dimensions of the eParticipation phenomenon are covered by a significant number of contributions, with neither side suffering from 
exceptional neglect. On the other hand, the impressive growth of contributions focusing on eParticipation effects and evaluation, which has tripled, can be linked to the progress of the many eParticipation initiatives started earlier on. As eParticipation projects move towards completion, research appears to move away from the description of activities and to focus on the evaluation of the impacts of such activities.

\section{1 eParticipation Actors}

Even though it is now the least focused on aspect in the sample analyzed, the focus on eParticipation actors has remained stable through time, in absolute terms. Moreover, the overall balance between different types of actors (government institutions, politicians, and voluntary organizations) has remained almost identical, with the exception of an increased focus on citizens. Without surprise, citizens and government institutions are the main object of the majority of the contributions focusing on actors. It appears that almost all of the overall slight increase of focus on actors in recent research is due to more studies investigating citizens as the main actors in eParticipation processes. Such a finding is in line with the rise of research interest on citizeninitiated eParticipation that would be expected as a consequence of the diffusion of web 2.0 applications occurred in the last five years. Web 2.0 applications, such as social networking services (SNS), wikis, and blogs, can in fact be argued to have the potential of putting the citizen as user of government services at the centre of ICTenabled participatory processes [11]. Our analysis can provide some evidence of this shift, even if it is still in its nascent phase. On the other hand, surprisingly few contributions focus specifically on the design, adoption, management, and use of web 2.0 tools in an eParticipation setting. Most of the studies still investigate, for instance, traditional institutional websites and government-run discussion fora. Overall, a large part of the body of research appears to still reflect a top-down approach to eParticipation that has government, and not citizens, as the main focus.

Moreover, it is worth noting that there is a persistent neglect of the role of researchers and scholars in eParticipation activities. The design phase in eParticipation initiatives, as an example, is crucial, and there is little doubt that researchers can play an important part in it [12]. Moreover, the benefits of adopting an engaged scholarship perspective in research [13], by involving practitioners and stakeholders in the research process, especially in research on IT in government [14], should clearly trigger the need to include researchers as a key actor in eParticipation activities.

\section{2 eParticipation Activities}

Focus on eParticipation activities, overall, has decreased. Within this focus, studies on eActivism, eCampaining and ePetitioning are still at the periphery of the body of research on eParticipation activities. The focus on online political discourse and online decision making has decreased in both absolute and relative terms in recent years.

The sample analyzed shows that the use of ICT for voting purposes is receiving increasing attention. While other "E"-political activities (activism, campaigning, petitioning) further decreased their already weak focus from research, eVoting appears to be the only eParticipation activity that has increased its appeal to researchers through 
time. Nevertheless, it is to be noted that the majority of the contributions on eVoting consist of design proposals for voting systems, while only a few are research contributions in a strict sense.

\subsection{Contextual Factors}

The number of studies focusing on contextual factors affecting eParticipation has remained identical, with 42 contributions focusing on this aspect in the two periods compared. The main change occurred in time has been the concentration of almost all contributions that deal with contextual factors on the role of underlying technologies, and of governmental organization, at the expense of all other factors. In the first period of eParticipation research a number of independent variables was explored in the literature to a more balanced extent. The impact of a wider range of factors was focused on, including policy and legal issues, information availability, infrastructure, and accessibility. Through time, it is striking to see how aspects such as accessibility and information availability have disappeared from the research agenda, leaving room for contributions focusing only on how technologies and governmental organization as independent variables affect eParticipation processes.

This steady strong focus by researchers on the role of government in eParticipation is in line with findings related to research on key actors as outlined above, and highly relevant as far as the discrepancy between these findings and the growing visibility of the web 2.0 discourse is concerned. Again, it seems as the increasingly popular stress on the central role of citizens as users, that many see as brought about by the concept of web 2.0, does not match the actual research focus of eParticipation.

\section{4 eParticipation Effects and Evaluation}

The most dramatic shift in the overall research focus has occurred in relation to the study of eParticipation effects and to eParticipation evaluation. First, the share of contributions focusing on eParticipation effects and evaluation has grown remarkably in the last five years. Second, the distribution of focuses within this share, which mainly concentrated on civic engagement effects, is now much more evenly balanced, with different types of evaluation studies and different types of eParticipation effects focused on to comparable extents.

As far as effects are concerned, recent research shows a vast increase of the share of contributions focusing on the deliberative effects of eParticipation, which was neglected in previous years. There has been a shift of focus from the sheer amount of participation towards a deeper insight into the impacts of ICT on the quality of democratic discussion. This can also be used as an interpretative key for looking at eParticipation evaluation research. The share of contributions focusing on the evaluation of eParticipation has, overall, almost doubled. Within this share, studies focusing on quantity of eParticipation have decreased and, at the same time, there has been a remarkable growth of contributions assessing the tone and style of online activities. These two phenomena can be interpreted as two sides of a single trend: as the focus on deliberative effects increases, so does the use of methods of evaluation that assess the tone and style of online discourses occurring within deliberation activities. Last, a new category of studies evaluating the degree of transparency and openness of 
eParticipation platforms has been introduced, to account for the emergence of this type of focus within the area of eParticipation evaluation studies. A relevant number of contributions focus on evaluating the extent to which eParticipation initiatives result in increased transparency and openness of actors, policies, and processes.

\section{Conclusions}

This article has provided an overview and a longitudinal analysis of the development of the rapidly growing research field of eParticipation, drawing on previous literature analysis work [5]. The analysis of the most recent literature contributions, based on 123 selected research articles from internationally acknowledged sources, has led to identifying the transformation occurring in the field, regarding research focuses and approaches. The choice of drawing on an existing framework of analysis of the literature provides the eParticipation research community with a first longitudinal analysis of the field, not only to capture the characteristics of this area in a given point in time, but also to enable a characterization of the field development through time.

Findings point out that, overall, the eParticipation research area shows great dynamism. The number of contributions in the field has grown remarkably, and encompasses a wide range of perspectives. The research agenda has changed in time, and it did so radically in some aspects. Some changes, in particular, are of counterintuitive nature, when compared with existing popular assumptions on the impacts of ICT on participation, and the transformation of democratic systems. This is the case, for instance, of studies on eParticipation activities, contextual factors, and effects. Such key areas, which represent the core of a research field, have experienced dramatic shifts. Some of them can be argued to be, to some extent, more predictable or less surprising than others.

The findings summarized in the previous section can be read as a basis for providing inputs to a research agenda, grounded on the gaps, trends and potentials of current eParticipation research.

\section{Focus on a wider range of contextual factors beyond the technological ones}

It can be argued that one of the indicators of the maturity of a research field is its internal balance between different focuses on actors, activities, contextual factors, and effects. In the eParticipation research field we are witnessing, overall, a move towards a more balanced distribution of focuses as far as these macro-categories are concerned. Within the domains of actors, activities, contextual factors, and effects, this is also happening as far as eParticipation effects is concerned. On the other hand it is striking to see how, within research on contextual factors affecting eParticipation, the field has moved from featuring a wide range of factors to focus on, to an almost exclusive focus on underlying technology determinants. While contributions often formally highlight the dangers of technological determinism, and call for a deeper, more sophisticated view on contextual factors affecting eParticipation processes, the large majority of studies that should do so have instead focused solely on technological determinants. Future research on eParticipation should revert this trend by including a stronger focus on important factors such as policy and legal issues, accessibility, and information availability. It is difficult to argue that traditional digital divide factors, 
such as the role of infrastructure or of information availability, will not play a role in eParticipation in the near future. As eParticipation initiatives spread in different countries, research should make an effort in diversifying the array of contextual factors that can explain the success or failure of IT initiatives aimed at improving citizen democratic participation.

\section{Encourage the shift of research focus from government to citizens and other stake- holders.}

The array of actors focused in eParticipation activities is to be extended. With the emergence of Web 2.0 platforms supporting eParticipation, theoretically citizens have the potential of becoming the main actors of eParticipation activities. Collaborative platforms, such as wikis, the horizontal distribution of communication channels in social networking services (SNS), and the emergence of platforms based on usergenerated content, ideally make it easier for citizens to coordinate, communicate, produce, and share political power vis-à-vis the traditional government institutions dedicated to decision-making. The amount of research attention on these new types of grassroots participatory experiences has increased in the past years, but it is still largely lagging behind the mushrooming of initiatives that are occurring in the real world, and the exponential boom in popularity of tools that carry this potential, such as in the examples of Twitter, Facebook, and the likes.

Moreover, the shift of focus from top-down, government-led towards bottom-up, citizen-led eParticipation initiatives must be accompanied by an extension of the range of actors to be focused on in research. It can be strongly argued that no longer do only government institutions, politicians, and citizens form the triangle of eParticipation activities, but that there are also voluntary organizations, industry players, and researchers themselves that are an important part of eParticipation processes. The need for digital participatory processes to be as inclusive as possible increases with the increase in complexity of the policy issues to be decided upon, and with the spread of the access to the technological capabilities that enable them.

\section{References}

1. Macintosh, A., Coleman, S., Schneeberger, A.: eParticipation: The Research Gaps. In: Macintosh, A., Tambouris, E. (eds.) ePart 2009. LNCS, vol. 5694, pp. 1-11. Springer, Heidelberg (2009)

2. Parvez, Z., Ahmed, P.: Towards building an integrated perspective on e-democracy. Information, Communication \& Society 9, 612-632 (2006)

3. Freschi, A.C., Medaglia, R., Nørbjerg, J.: A Tale of Six Countries: eParticipation Research from an Administration and Political Perspective. In: Macintosh, A., Tambouris, E. (eds.) ePart 2009. LNCS, vol. 5694, pp. 36-45. Springer, Heidelberg (2009)

4. Medaglia, R.: The challenged identity of a field: The state of the art of eParticipation research. Information Polity: The International Journal of Government \& Democracy in the Information Age 12, 169-181 (2007)

5. Sæbø, Ø., Rose, J., Skiftenes Flak, L.: The shape of eParticipation: Characterizing an emerging research area. Government Information Quarterly 25, 400-428 (2008)

6. Sanford, C., Rose, J.: Characterizing eParticipation. International Journal of Information Management 27, 406-421 (2007) 
7. Webster, J., Watson, R.T.: Analyzing the Past to Prepare for the Future: Writing a Literature Review. Management Information Systems 26, xiii-xxiii (2002)

8. Macintosh, A.: Characterizing e-participation in policy-making. In: Proceedings of the 37th Annual Hawaii International Conference on System Sciences, pp. 117-126 (2004)

9. Yildiz, M.: E-government research: Reviewing the literature, limitations, and ways forward. Government Information Quarterly 24, 646-665 (2007)

10. Ricciardi, F., Lombardi, P.: Widening the Disciplinary Scope of eParticipation. Reflections after a Research on Tourism and Cultural Heritage. In: Tambouris, E., Macintosh, A., Glassey, O. (eds.) ePart 2010. LNCS, vol. 6229, pp. 140-150. Springer, Heidelberg (2010)

11. Sæb $\varnothing, \varnothing$., Rose, J., Nyvang, T.: The Role of Social Networking Services in eParticipation. In: Macintosh, A., Tambouris, E. (eds.) ePart 2009. LNCS, vol. 5694, pp. 46-55. Springer, Heidelberg (2009)

12. Sanford, C., Rose, J.: Designing the e-participation artefact. International Journal of Electronic Business 6, 572-589 (2008)

13. Van de Ven, A.H.: Engaged scholarship: a guide for organizational and social research. Oxford University Press, Oxford (2007)

14. Medaglia, R.: Engaged Scholarship in Research on Information Technology in Government: Stuck in the Ivory Tower? Information, Communication \& Society (forthcoming) 